\title{
MACROELEMENT NUMERICAL SIMULATION OF THE SEISMIC RESPONSE OF A TIMBER-RETROFITTED MASONRY PIER
}

\author{
M. MIGLIETTA ${ }^{1 *}$, N. DAMIANI ${ }^{1}$, S. BRACCHI ${ }^{2}$, G. GUERRINII ${ }^{2,3}$, \\ F. GRAZIOTTII ${ }^{2,3}$ AND A. PENNA ${ }^{2,3}$ \\ ${ }^{1}$ Understanding and Managing Extremes (UME) Graduate School \\ Istituto Universitario degli Studi Superiori di Pavia (IUSS Pavia) \\ Piazza della Vittoria 15, 27100 Pavia, Italy \\ Email: marco.miglietta@iusspavia.it - nicolo.damiani@iusspavia.it \\ Web page: http://www.iusspavia.it \\ ${ }^{2}$ Dept. of Civil Engineering and Architecture (DICAr) \\ University of Pavia, via Ferrata 3, 27100 Pavia, Italy \\ Email: stefano.bracchi@unipv.it - gabriele.guerrini@unipv.it - francesco.graziotti@unipv.it - \\ andrea.penna@unipv.it - Web page: http://dicar.unipv.it/ \\ ${ }^{3}$ European Centre for Training and Research in Earthquake Engineering (EUCENTRE) \\ Via Ferrata 1, 27100 Pavia, Italy \\ Email: gabriele.guerrini@eucentre.it - francesco.graziotti@eucentre.it - andrea.penna@eucentre.it \\ Web page: https://www.eucentre.it/
}

Keywords: Failure modes, in-plane shear-compression tests, nonlinear macroelement, numerical simulation, timber retrofit, unreinforced masonry.

\begin{abstract}
In the North-East part of The Netherlands, induced seismicity due to gas extraction is affecting a local building stock consisting mainly of unreinforced masonry (URM) houses not designed for earthquake resistance. Experimental and numerical studies conducted at EUCENTRE, Pavia (Italy), have demonstrated that buildings with URM cavity-walls structural systems are among the most vulnerable existing Dutch construction typologies. A light and reversible retrofit system made of timber frames and oriented-strands boards was then designed and tested to increase the in-plane and out-of-plane capacities of masonry piers and to enhance their connections with the floor diaphragms. The development of modelling approaches able to simulate the influence of the retrofit system is of fundamental importance for future applications to real-case existing buildings and for vulnerability studies on different building stocks. Based on two quasi-static in-plane shear-compression tests on two full-scale masonry piers, one in bare and one in retrofitted configuration, a specific macroelement was calibrated to simulate the bare pier lateral response and the effects of the retrofit on the in-plane flexural and shear capacities. This paper discusses the adopted modelling strategies and the comparison between numerical and experimental results.
\end{abstract}

\section{INTRODUCTION}

In recent years, human activities or natural phenomena (e.g. gas extraction $[1,2,3]$ or slip of unknown faults [4]) have demonstrated the possibility that areas historically considered not 
prone to seismic events can be subjected to earthquakes. Due to the unexpected nature of such occurrences, they usually hit regions where buildings do not typically incorporate seismic details, and therefore are highly vulnerable to lateral loads. Unreinforced masonry (URM) buildings constitute one of the most sensitive structural typologies in these areas; moreover, they usually include cultural heritage buildings and thus deserve particular attention.

Aiming at preserving these structures, several retrofit techniques have been developed for URM buildings in seismic regions. Some of them are based on the application of an additional material layer to the masonry [5,6], other ones on the application of steel profiles or of posttensioning [7]. Furthermore, the seismic behavior of URM buildings can be effectively improved by enhancing the connections between masonry walls and floor systems $[8,9]$. However, structural strengthening in low-seismicity areas needs to be sustainable, light, reversible, and cost-effective.

A new retrofit system consisting of timber frames and oriented strand boards (OSB) was proposed and investigated through quasi-static in-plane shear-compression tests on two identical calcium-silicate (CS) masonry piers, one bare and one strengthened [10]. The experimental lateral responses of the specimens were then simulated with the software TREMURI by means of nonlinear macroelements. This paper focuses on the basic assumptions behind the nonlinear models and discusses the simulation of the response of the two piers. This study is part of a comprehensive experimental campaign aiming at the assessment and mitigation of the seismic vulnerability of URM buildings in the Groningen region of The
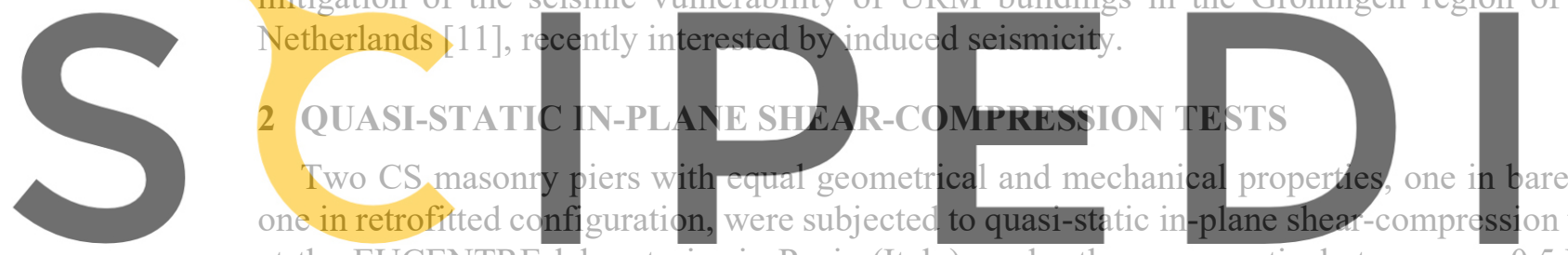

at the EUCENTRE laboratories in Pavia (Italy), under the same vertical stress $\sigma_{v}=0.5 \mathrm{MPa}$

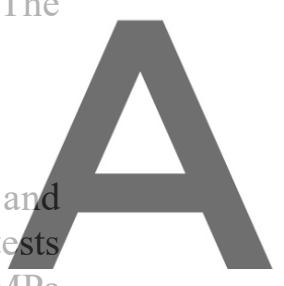

Register for and double-fixed boundary conditions. A detailed discyssion on the strengthening intervention

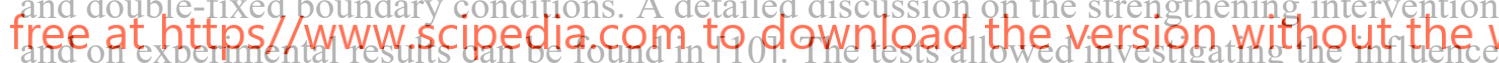
of the newly proposed timber retrofit system on the lateral capacity of the bare masonry pier. The campaign was complemented by mechanical characterization tests on masonit, bricks, and mortar.

\subsection{Overview of the specimens and material properties}

The specimens represented a first-storey loadbearing pier from the prototype of a URM Dutch terraced-house end-unit tested at the EUCENTRE facilities [11]. The building prototype consisted of URM cavity-walls, with a single-wythe internal loadbearing CS leaf and a singlewythe external clay veneer with no structural function. The specimens consisted of 33 courses of CS bricks, with average dimensions of $210 \times 100 \times 70 \mathrm{~mm}$, and 10-mm-thick mortar joints, resulting in height $H=2.70 \mathrm{~m}$, length $L=2.00 \mathrm{~m}$, and thickness $t=0.10 \mathrm{~m}$ (Figure 1). The clay outer-leaf was not included because irrelevant for the seismic capacity of the specimens. The walls were built simultaneously and matured under the same environmental conditions, after which, on one of the two was strengthened.

The retrofit system consisted of a timber frame made of vertical posts and horizontal blockings, fastened to the masonry (Figure 1b, c and d). Horizontal top and bottom sill plates allowed 
connecting the frame to reinforced concrete (RC) footing and top beam. All timber elements had a section of $60 \times 80 \mathrm{~mm}$, where the $60-\mathrm{mm}$ dimension was oriented perpendicular to the wall. Steel tie-down connections were provided between posts and RC top and bottom elements through the sill plates, to ensure in-plane flexural and sliding resistance. 18-mm-thick OSB were nailed to the timber frame to enhance the pier shear capacity.

The masonry mechanical parameters of interest, obtained from characterization tests, are reported in Table 1. The timber was red solid fir (Picea-abies) of class S10/C24 [12] with a density of $517 \mathrm{~kg} / \mathrm{m}^{3}$, mean Young modulus $E_{0, \text { mean }}=11000 \mathrm{MPa}$ and shear modulus $G_{0, \text { mean }}=690 \mathrm{MPa}$, and characteristic tensile strength parallel to the fibers $f_{t, 0}=14 \mathrm{MPa}$. The OSB were classified as OSB/3 [13] with a density of $572 \mathrm{~kg} / \mathrm{m} 3$. Tie-down connectors had a characteristic tensile strength of $11.6 \mathrm{kN}$ [14].

\subsection{Experimental results}

The unstrengthened specimen exhibited a hybrid flexural and shear-sliding response (Figure $2 \mathrm{a})$. The development of a full-length crack between the $32^{\text {nd }}$ and $33^{\text {rd }}$ brick courses at a drift ratio (top displacement divided by $H$ ) of $0.20 \%$ determined the transition from flexural rocking to shear sliding. The lateral strength reached its peak of $78 \mathrm{kN}$ at this drift ratio, then it decreased to a residual value of about $65 \mathrm{kN}$. The test was interrupted when the specimen lost its vertical load-bearing capacity at an ultimate drift of $0.75 \%$.
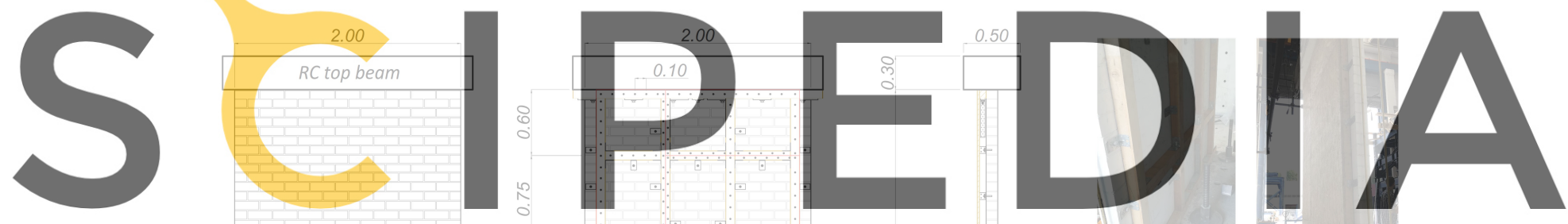

Register for free at https//wwvis scipedia.com to download the version without the watermark

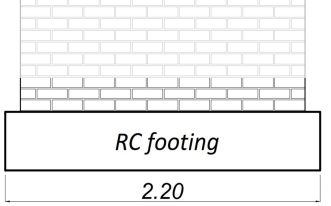

a)

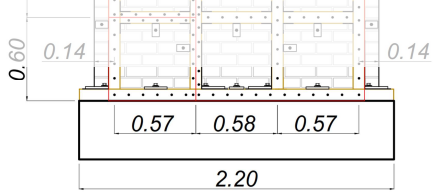

b)

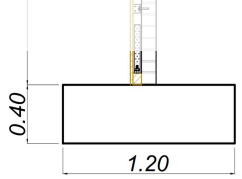

c)

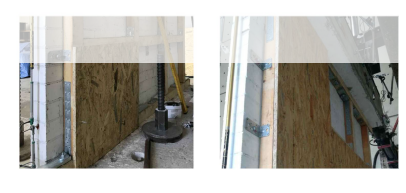

d)

Figure 1: Specimen geometries and details: a) bare pier; b, c, d) retrofitted pier.

Table 1: Masonry mechanical properties.

\begin{tabular}{ccc}
\hline & Mean & C.o.V. \\
\hline Density $(\rho)$ & $1836 \mathrm{~kg} / \mathrm{m}^{3}$ & 0.01 \\
Compressive strength $\left(f_{m}\right)$ & $10 \mathrm{MPa}$ & 0.06 \\
Young modulus $\left(E_{m}\right)$ & $6593 \mathrm{MPa}$ & 0.09 \\
Initial shear strength $\left(f_{v 0}\right)$ & $0.62 \mathrm{MPa}$ & - \\
Shear friction coefficient $(\mu)$ & 0.71 & - \\
\hline
\end{tabular}


The retrofitted specimen exhibited 35\%-higher strength and 166\%-higher displacement capacity compared to the bare pier. The maximum lateral force of $105 \mathrm{kN}$ was reached at a drift ratio of $0.8 \%$. The retrofit prevented shear sliding and forced a flexural rocking response up to $1.0 \%$ drift ratio. The pier strength decreased during the last two sets of cycles upon diagonal shear cracking of the masonry. The test was terminated at a drift of $2.0 \%$ when the timber system was supporting most of the applied vertical load. It is worth noting that both specimens exhibited a first cracking drift ratio of $0.075 \%$ : the strengthening system did not have any effect on the first cracking due to its lower stiffness compared to the masonry.

\section{NUMERICAL SIMULATION OF THE TESTS}

The assessment of the seismic vulnerability of buildings requires reliable numerical models capable to capture the main features of the actual structural response. For this reason, twodimensional numerical models of the tested piers were built and validated against the experimental results using the software TREMURI [15], which employs nonlinear macroelements [16]. Each pier was discretized in a series of macroelements of equal length, as proposed by [17] to model reinforced masonry. This strategy was adopted to capture the effect of the timber posts (Figure 1) on the axial-flexural response of the pier: in fact, they act as longitudinal reinforcement bridging cracks. The rotations of top and bottom nodes were restrained to impose double-fixed boundary conditions.
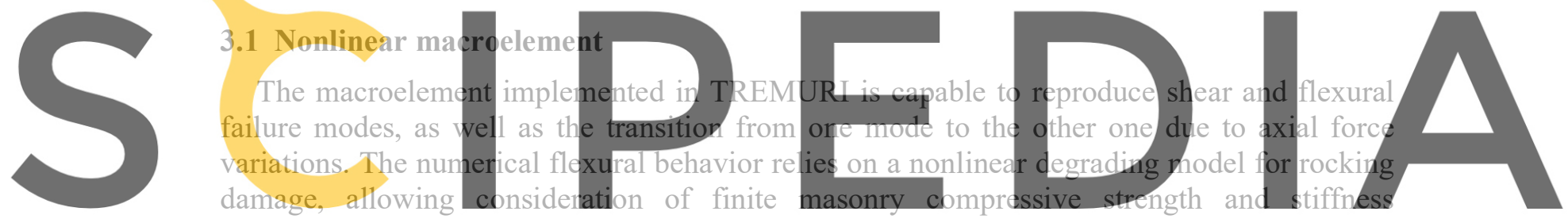
degradation due to toe-crushing (Figure 3a).

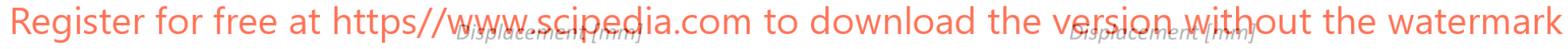

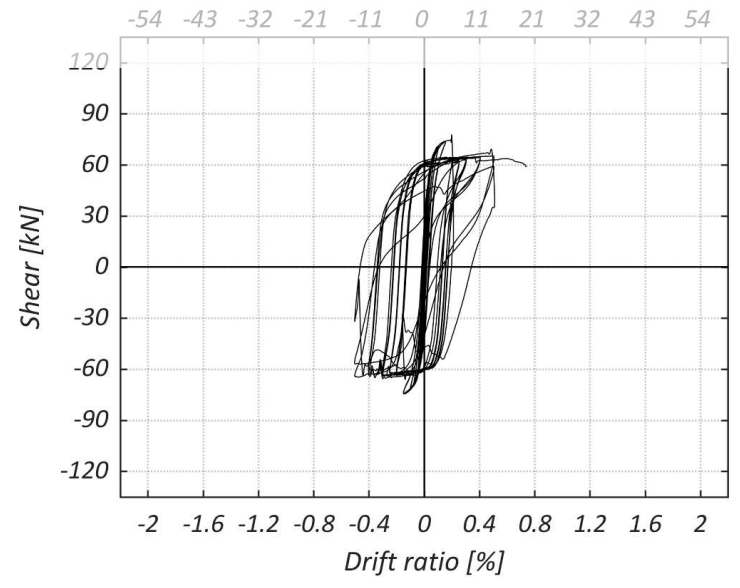

a)

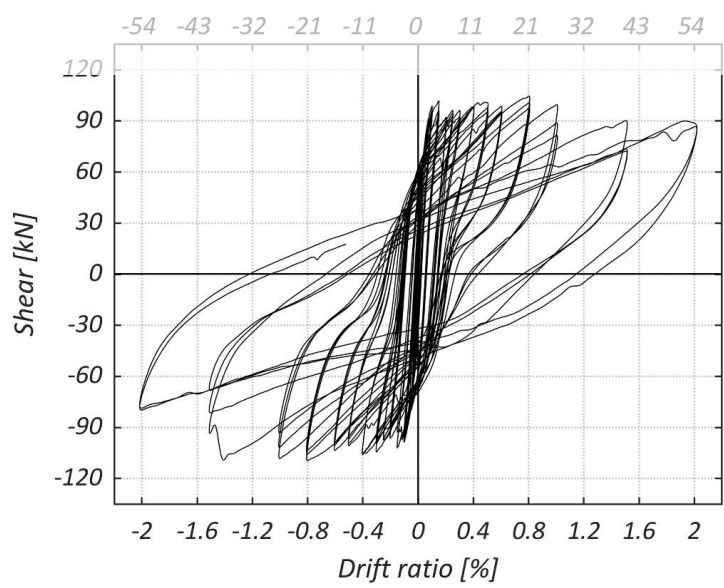

b)

Figure 2: Experimental hysteretic responses: a) bare pier; b) retrofitted pier. 


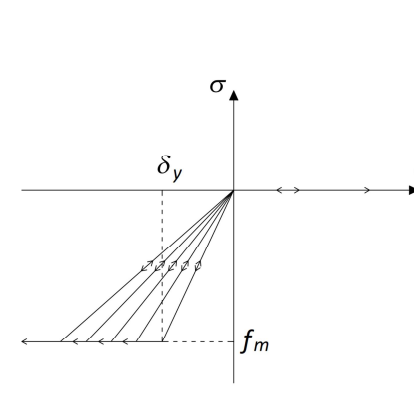

a)

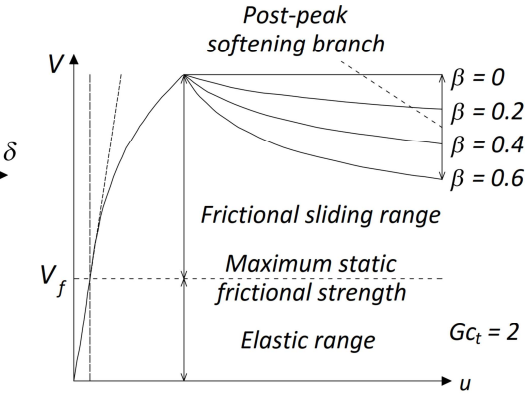

b)

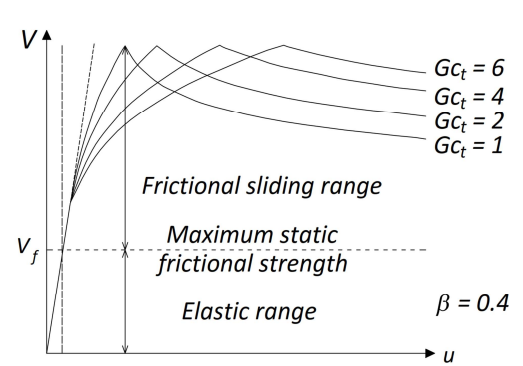

c)

Figure 3: Nonlinear macroelement behavior: a) nonlinear flexural degrading model; b) role of parameter $\beta$ on the shear model; c) role of parameter $G c_{t}$ on the shear model.

The shear model is characterized by elastic, inelastic, and sliding ranges, with a post-peak softening branch that tends asymptotically to a residual static frictional strength. Parameters $\beta$ (softening parameter, Figure $3 \mathrm{~b}$ ) and $G c_{t}$, (nonlinear deformability parameter, Figure $3 \mathrm{c}$ ) control the transition from peak to residual shear strength and the displacement at peak strength, respectively. For all shear failure criteria presented in the following paragraph, $\beta$ and $G c_{t}$ were kept constant as 0.5 and 1.1 , respectively.
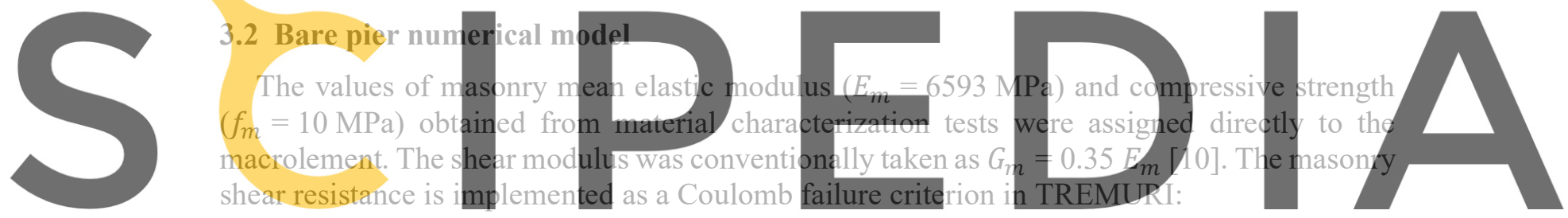
where $L$ and $t$ are the length and thickness of the pier; $\tilde{f}_{v 0, \text { mas }}$ is the equivalent initial shear strength parameter; $\tilde{\mu}_{\text {mas }}$ is the equivalent friction coefficient; and $\sigma_{v}$ is the mean compression stress applied on the pier.

Four different strategies were followed to calculate the equivalent parameters $\tilde{f}_{v 0, \text { mas }}$ and $\tilde{\mu}_{\text {mas }}$. The first two cases were obtained by computing them from the diagonal shear failure criterion for regular masonry, according to the Italian building code [18]:

$$
V_{R d}=\frac{L \cdot t}{b} \cdot\left(\frac{f_{v 0}}{1+\mu \cdot \Phi}+\frac{\mu}{1+\mu \cdot \Phi} \cdot \sigma_{v}\right)
$$

where $b$ is a coefficient depending on the pier slenderness, which can by assumed equal to 1.5 ; $t$ is thickness of the pier; $f_{v 0}$ is the initial shear strength of the masonry material; and $\mu$ is the shear friction coefficient of the masonry material. Parameter $\Phi$ is the average slope of a stairstepped crack computed as:

$$
\Phi=\frac{2 h_{\text {brick }}}{b_{\text {brick }}}
$$


where $b_{\text {brick }}$ and $h_{\text {brick }}$ are the length and height of a brick in the shear plane. Equivalent initial shear strength and equivalent friction coefficient are then defined as:

$$
\begin{gathered}
\tilde{f}_{v 0, \text { mas }}=\frac{f_{v 0}}{b \cdot(1+\mu \cdot \Phi)} \\
\tilde{\mu}_{\text {mas }}=\frac{\mu}{b \cdot(1+\mu \cdot \Phi)}
\end{gathered}
$$

Two cases stemmed from this approach, using either the standard mechanical properties suggested by the code or the actual values obtained through material characterization tests (Table 1). Substituting the experimental masonry mechanical properties (Table 1) into equations 3.4 and 3.5 , values $\tilde{f}_{v 0, \text { mas }}=0.28 \mathrm{MPa}$ and $\tilde{\mu}_{\text {mas }}=0.32$ were obtained. In the second case, the friction coefficient $\mu=0.577$ suggested by the Italian code [18] was adopted, while keeping the experimental value $f_{v 0}=0.61 \mathrm{MPa}$; this resulted in equivalent parameters $\tilde{f}_{v 0, \text { mas }}=0.3 \mathrm{MPa}$ and $\tilde{\mu}_{\text {mas }}=0.28$.

Similarly, two other cases were derived based on the shear-sliding failure criterion, defined as $[19,20]$ :

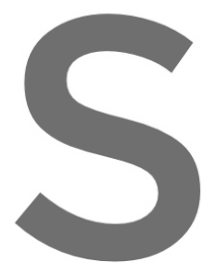

$$
V_{R d}=V_{R, f v o}+V_{R, \mu}=L \cdot t \cdot\left(\frac{f_{v 0} \cdot L_{C}}{L}+\mu \cdot \sigma_{v}\right)
$$

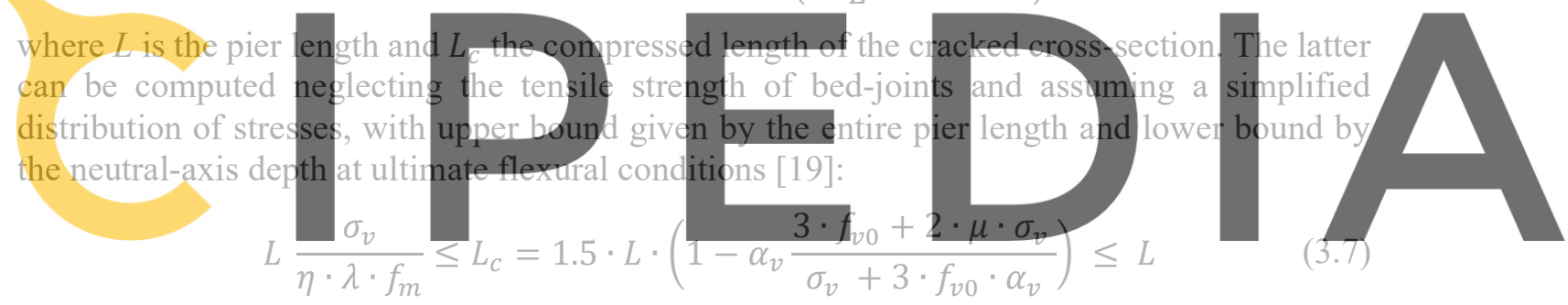

The equivalent friction coefficient ( $\widetilde{\mu}_{m a s}$ ) in this case coincides with the material one, while the equivalent initial shear strength can be obtained as:

$$
\tilde{f}_{v 0, \text { mas }}=\frac{f_{v 0} \cdot L_{c}}{L}
$$

In one case, substituting the experimental initial shear strength (Table 1) in equation 3.8, a value $\tilde{f}_{v 0, \text { mas }}=0.045 \mathrm{MPa}$ was calculated, to be used in combination with experimental $\tilde{\mu}_{\text {mas }}=\mu=0.71$. In the other case, the equivalent initial shear strength was still derived from experimental properties as $\tilde{f}_{v 0 \text {, mas }}=0.045 \mathrm{MPa}$, while the equivalent friction coefficient $\tilde{\mu}_{\text {mas }}=\mu=0.4$ was taken according to the Italian building code [18].

\subsection{Retrofitted pier numerical model}

Starting from the outcomes of the bare pier calibrated model, the simulation of the retrofitted specimen experimental response required additional considerations. The connections between masonry and timber grant deformation compatibility, with the actual mechanism controlled by 
the lower total strength of the combined masonry/timber system. Furthermore, the flexural and shear strength contributions of the timber system need to be modelled separately since they are provided by different components. While the former is governed by yielding of tie-down connections between vertical posts and RC top beam and footing, the latter is given only by the nailed OSB.

In light of these considerations, the vertical posts were modelled by nonlinear beam elements, discretized in segments of equal length and connected to the same top, bottom, and intermediate nodes as the discretized macroelements (Figure 4). The intermediate segments of each post were assigned the timber member properties: mean elastic moduli $\left(E_{0, \text { mean }}=11000 \mathrm{MPa}\right.$ and $\left.G_{0, \text { mean }}=690 \mathrm{MPa}\right)$, characteristic tensile strength $\left(f_{t, 0}=14 \mathrm{MPa}\right)$, and cross-sectional area and moment of inertia $\left(A_{p}=4800 \mathrm{~mm}^{2}\right.$ and $\left.I_{p}=2.56 \times 10^{6} \mathrm{~mm}^{4}\right)$. Instead, the top and bottom end-segments were modelled with equivalent elastic moduli ( $E_{e q}=11732 \mathrm{Mpa}$ and $\left.G_{e q}=4106 \mathrm{MPa}\right)$ and strength $\left(f_{y, e q}=2.66 \mathrm{MPa}\right)$, computed to restitute the actual axial forcedisplacement relationship of the tie-down connector over its free length between fasteners, assigning cross-sectional area $A_{p}$ as for the timber members and zero moment of inertia. The equivalence on the material properties was required by the different end-segment lenght and cross-sectional area, compared to the actual free length and resisting area of the steel connector. Before calculating $f_{y, e q}$, a factor 1.1 was applied to the characteristic yield strength of the connector to estimate its expected value [21].
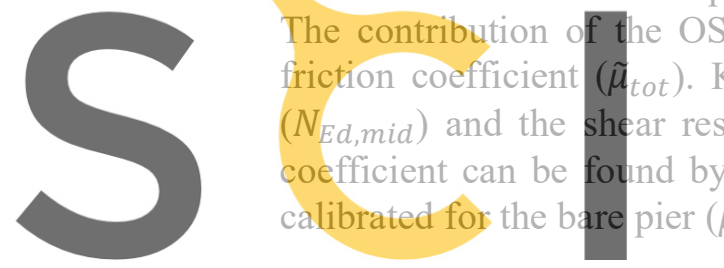

Register for free at https//www.scipedia.com to dowwmatb

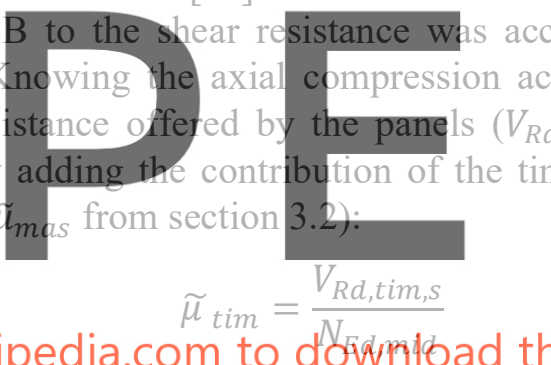

$$
\tilde{\mu}_{\text {tot }}=\tilde{\mu}_{\text {mas }}+\tilde{\mu}_{\text {tim }}
$$

Given the axial compression $N_{E d, m i d}=106 \mathrm{kN}$ and the expected panel shear strength $V_{R d, \text { tim }, \mathrm{s}}=45 \mathrm{kN}[10,21,22]$, equation 3.9 resulted in $\widetilde{\mu}_{\text {tim }}=0.42$.

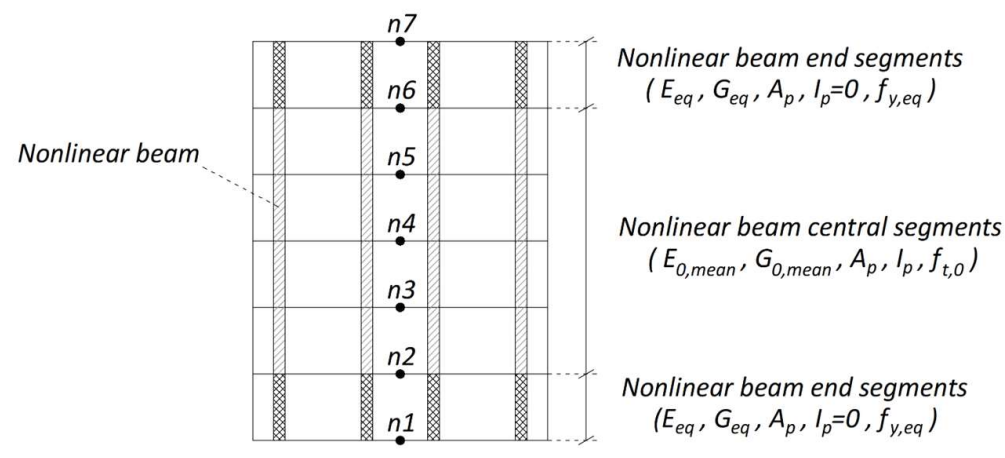

Figure 4: Retrofitted pier model. 


\subsection{Calibration of the models}

The results of both simulations based on the diagonal shear failure criterion showed very similar numerical responses, initially governed by a flexural behavior followed by a shearsliding one (Figure 5a and $\mathrm{b}$ ). While the flexural part approximates well the experimental response, the transition to shear-sliding was predicted at an earlier drift ratio than in reality. Moreover, the predicted residual shear strength was lower than the experimental one, and the strength drop from rocking to sliding behavior appeared overestimated, denoting an excessive influence of the cohesive contribution to the total strength of the pier.

Looking at the numerical results of the two models based on the shear-sliding failure criterion, two essentially different outcomes were obtained. The use of the friction coefficient from material characterization tests induced a flexure-only response (Figure 5c), denoting that the model was overestimating the shear-sliding resistance. On the other hand, the use of the equivalent friction coefficient suggested by the Italian code [18] led to a shear-only response, due to a significant underestimation of the specimen shear strength (Figure 5d): the flexural mechanism could not be activated in this case, since the shear-sliding resistance was too low and governed the response from the very beginning. However, comparing all numerical results, the models based on the shear-sliding failure criterion were deemed to be more appropriate since the real behavior of the bare pier was hybrid, with a transition from rocking to sliding, and no diagonal shear failure was triggered.

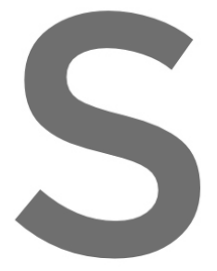

The experimental response of Figure of Figure 5d, but w was selected to obtair residual strength (65 resulted in an equival
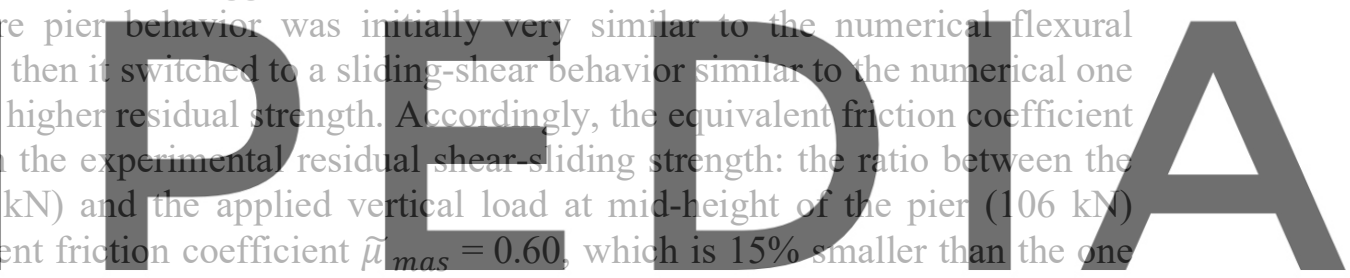

obtained from material characterization tests. The initial shear strength $\tilde{f}_{v 0, \text { mas }}=0.12 \mathrm{MPa}$ was

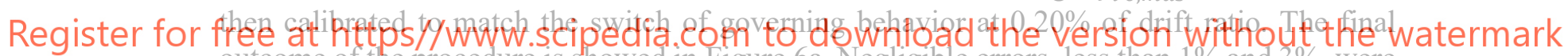
outcome of the procedure is showed in Figure 6a. Negligible errors, less than $1 \%$ and $3 \%$, were obtained in terms of simulated maximum and residual strengths, respectively.

Figure $6 \mathrm{~b}$ compares the numerical response of the retrofitted pier model with the experimental one. The strategy adopted to simulate the influence of the retrofit system on the bare pier capacity captured the experimental behavior with good approximation and did not require any calibration or iteration. Negligible errors, less than $4 \%$, were obtained in terms of specimen strength. Combining the elastoplastic hysteresis of the beam segments simulating tie-down connections, with the nonlinear elastic rocking response of the masonry pier, resulted in a flagshaped overall hysteretic behavior, which approached the actual dissipative response of the retrofitted pier. Minor discrepancies were observed because the additional energy dissipated by friction at crack interfaces and connections was not captured, as well as the initial accumulation of small residual displacements. Furthermore, the model was not able to reproduce the development of diagonal shear cracking beyond $1.0 \%$ drift ratio, which ultimately led to failure of the retrofitted specimen. Overall, despite these small discrepancies, the simulation successfully reproduced the experimental behaviour of the retrofitted pier. 
M. Miglietta, N. Damiani, S. Bracchi, G. Guerrini, F. Graziotti and A. Penna

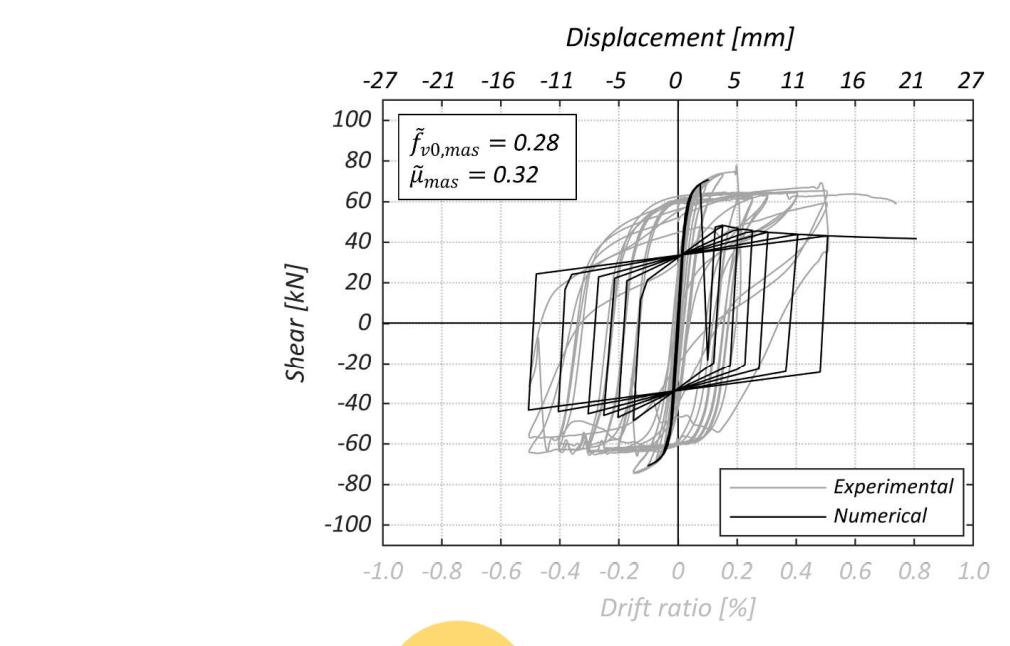

a)

Displacement [mm]

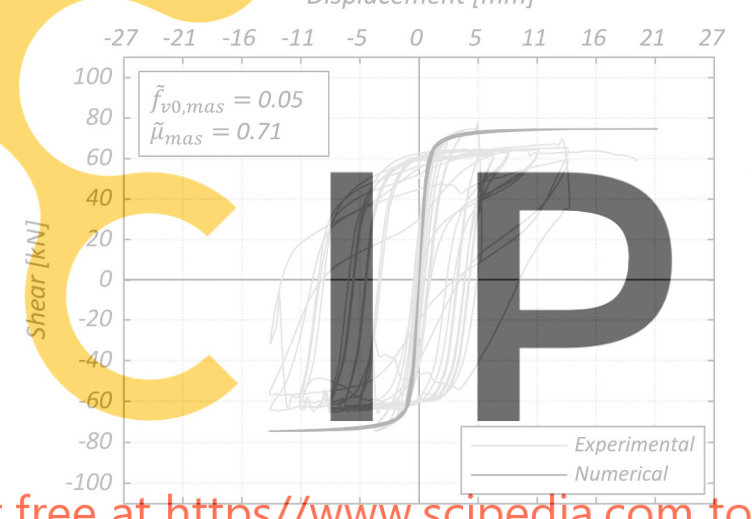

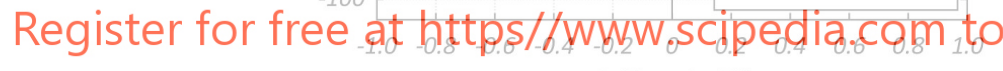

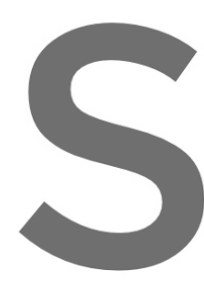

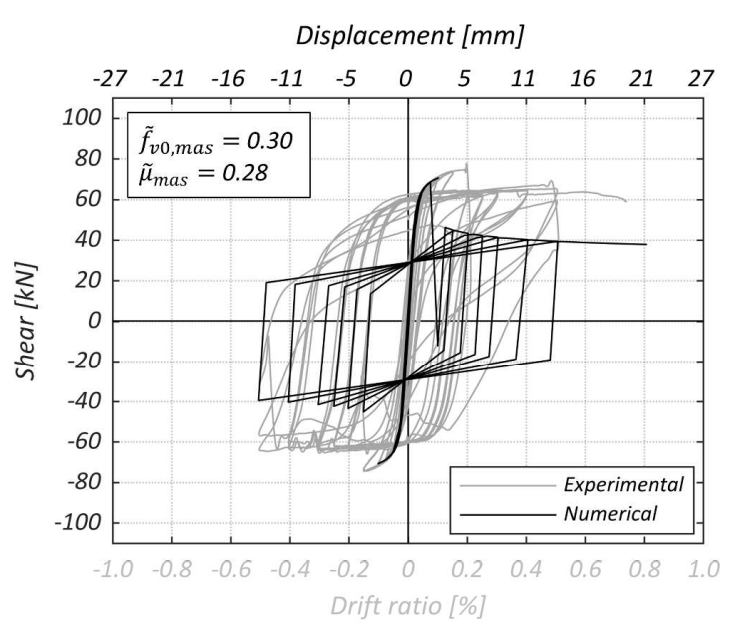

b)

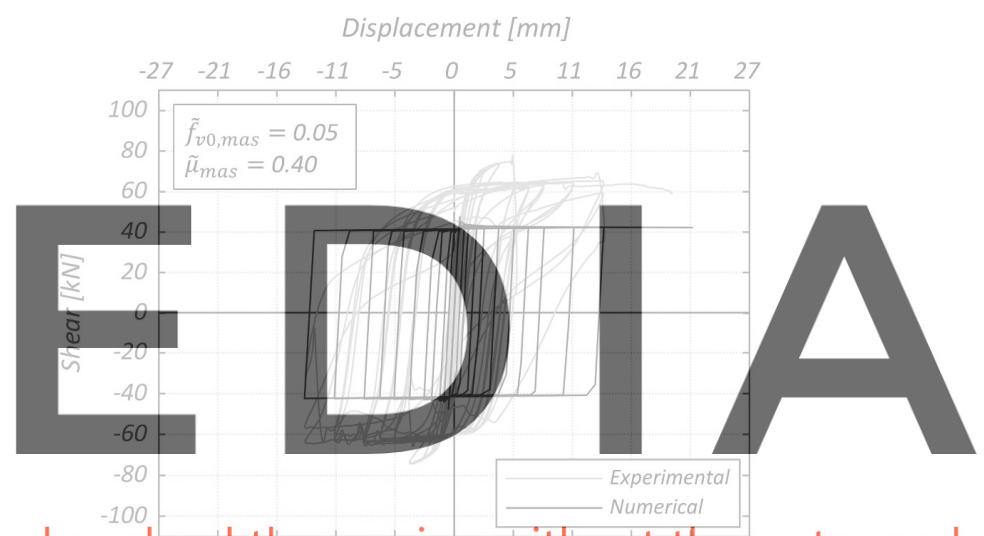

c)

\section{Drift ratio [\%]}

\section{Drift ratio [\%]}

d)

Figure 5: Bare pier numerical and experimental responses: a) diagonal shear failure criterion with friction coefficient from material characterization; b) diagonal shear failure criterion with friction coefficient suggested by [18]; c) shear-sliding failure criterion with friction coefficient from material characterization; d) shear-sliding failure criterion with friction coefficient suggested by [18]. 

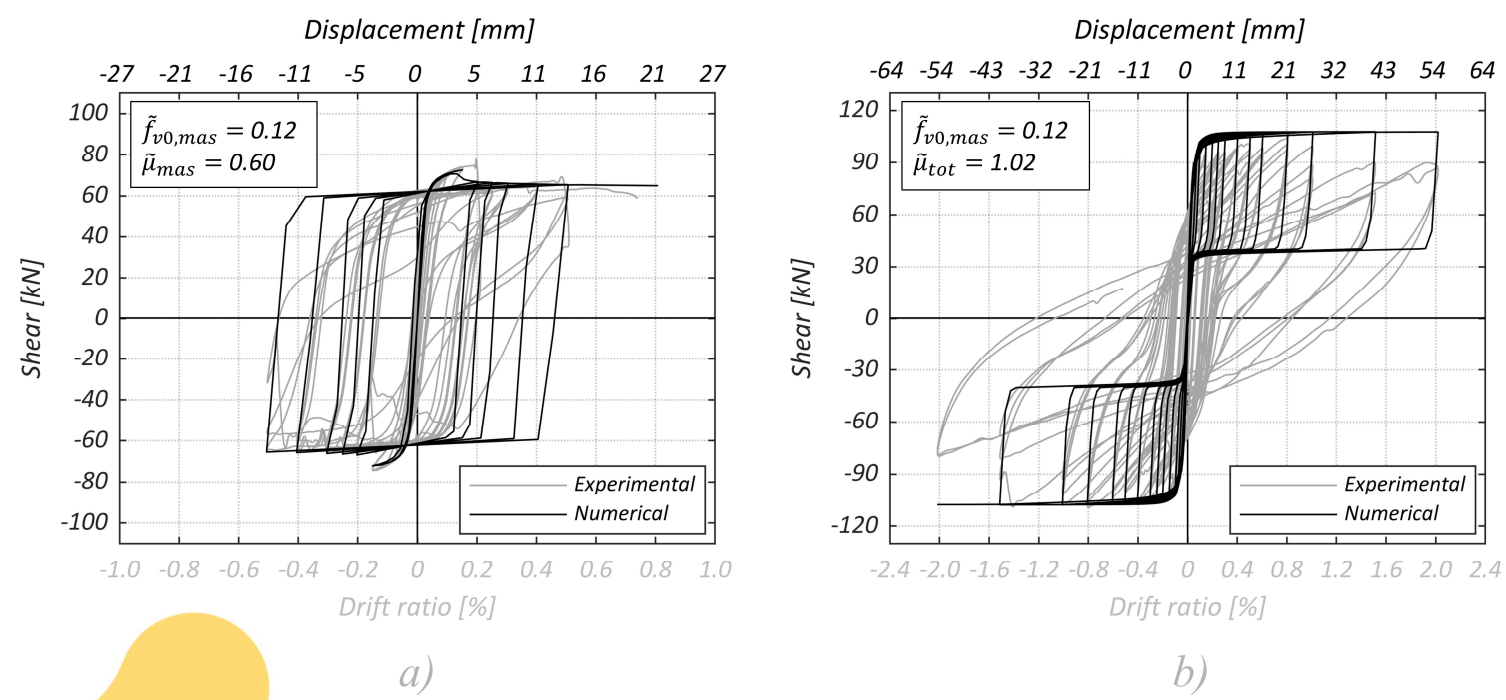

Figure 6: Numerical and experimental responses after model calibration: a) bare pier; b) retrofitted pier.

\section{CONCLUSIONS}

This paper discussed the numerical simulation of two in-plane shear-compression tests performed on two identical calcium-silicate nasonry piers, one in bare conditions and one retrofitted with a 1 mechanically connectron flexural capacity, and OSB pan The software TREMURI was used to simul nonlinear macroelements constituting the pi timber frames and their connections to RC footing and top beam.

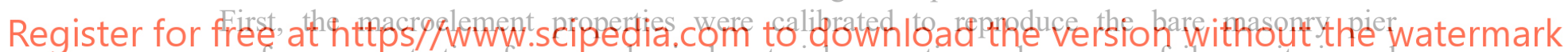
performance, starting from mechanical material properties and common failure criteria and applying some corrections. Recognizing a hybrid failure mode which transitioned from flexural rocking to sliding-shear, an equivalent friction coefficient was adopted based on the experimental residual lateral strength and applied axial compression. Then, the equivalent initial shear strength was calibrated to force the transition from rocking to sliding mode at $2.0 \%$ drift ratio, as recorded in the experiment. The masonry elastic modulus and compressive strength from material characterization did not require any adjustment. The peak and residual lateral strength of the bare pier were then captured with errors of less than $1 \%$ and $3 \%$, respectively.

After calibration of the bare masonry pier, additional considerations were necessary to reproduce the behavior of the retrofitted one. Vertical posts were explicitly modelled as nonlinear beam elements, discretized in segments and connected to the same top, bottom, and intermediate nodes as the discretized macroelements. The contribution to the shear resistance of the specimen, provided by the nailed OSB, was simulated instead by increasing the friction coefficient of the masonry macroelements. The numerical strength approached the experimental one with an error of less than $4 \%$, without any calibration or iteration, and reproduced with good approximation the flag-shaped hysteretic cycles. However, the model did not capture the 
development of diagonal shear cracking beyond $1.0 \%$ drift ratio, which ultimately led to failure of the retrofitted specimen.

Acknowledgements. This work is part of the EUCENTRE project "Study of the vulnerability of masonry buildings in Groningen", within the research programme framework on hazard and risk of induced seismicity in the Groningen province, sponsored by the Nederlandse Aardolie Maatschappij BV (NAM). The modelling activity was funded by the DPC-ReLUIS within the framework of the Work-Package-5 2019-2021: "Interventi di rapida esecuzione a basso impatto ed integrati". The authors would like to thank all parties involved in this project: the DICAr Laboratory of the University of Pavia and the EUCENTRE Laboratory, which performed the tests, the DPC-ReLUIS and the partner NAM.

\section{REFERENCES}

[1] Bourne, S.J., Oates, S.J., Bommer, J.J., Dost, B., van Elk, J., \& Doornhof, D. A Monte Carlo method for probabilistic hazard assessment of induced seismicity due to conventional natural gas production. Bulletin of the Seismological Society of America (2015) 105(3): 1721-1738.

[2] Crowley, H., Pinho, R., van Elk, J., \& Uilenreef, J. Probabilistic damage assessment of buildings due to induced seismicity. Bulletin of Earthquake Engineering (2019) 17(8): 4495-4516.

[3] Graziotti, F., Penna, A., \& Magenes, G. A comprehensive in situ and laboratory testing programme supporting seismic risk analysis of URM buildings subjected to induced earthquakes. Bulletin of Earthquake Engineering (2018) 17(8): 4575-4599.

[4] Horton Jr., J.W. \& Williams, R.A. The 2011 Virginia earthquake: What are scientists learning? Eos, Transactions American Geophysical Union (2012) 93(33): 317-318.

[5] Babaeidarabad, S., Arboleda, D., Loreto, G., \& Nanni, A. Shear strengthening of unreinforced concrete masonry walls with fabric-reinforced-cementitious-matrix. Construction and Building Materials (2014) 65: 243-253.

[6] Giaretton, M., Dizhur, D., Garbin, E., Ingham, J. M., \& da Porto, F. In-plane strengthening of clay brick and block masonry walls using textile-reinforced mortar. Journal of Composites for Construction (2018) 22(5): 04018028.

[7] Ma, R., Jiang, L., He, M., Fang, C., \& Liang, F. Experimental investigations on masonry structures using external prestressing techniques for improving seismic performance. Engineering Structures (2012) 42: 297-307.

[8] Podestà, S., \& Scandolo, L. Earthquakes and Tie-Rods: Assessment, Design, and Ductility Issues. International Journal of Architectural Heritage (2019) 13(3), 329-339.

[9] Senaldi, I. E., Guerrini, G., Comini, P., Graziotti, F., Penna, A., Beyer, K., \& Magenes, G. Experimental seismic performance of a half-scale stone masonry building aggregate. Bulletin of Earthquake Engineering (2019) 1-35.

[10] Guerrini, G., Damiani, N., Miglietta, M. \& Graziotti, F. Cyclic response of masonry retrofitted with timber frames and boards. Structures and buildings (2020) in press. DOI: 10.1680/jstbu.19.00134.

[11] Damiani, N., Miglietta, M., Mazzella, L., Grottoli, L., Guerrini, G., \& Graziotti, F. Fullscale shaking table test on a Dutch URM cavity-wall terraced-house end unit - A retrofit solution with strong-backs and OSB boards - EUCBUILD-7. Research report 
EUC052/2019U, (2019) EUCENTRE Pavia, Italy.

[12] European Committee for Standardization (CEN). EN 14081-1: Timber Structures. Strength graded structural timber with rectangular cross section. Part I: General requirements. European Committee for Standardization (2016), Brussels, Belgium.

[13] European Committee for Standardization (CEN). EN 300: Oriented Strand Boards (OSB). Definitions, classification and specifications (2006), Brussels, Belgium.

[14] Rothoblaas. Wood connectors and timber plates (2015). https://www.rothoblaas.com/catalogues-rothoblaas.

[15] Lagomarsino, S., Penna, A., Galasco, A., \& Cattari, S. TREMURI program: an equivalent frame model for the nonlinear seismic analysis of masonry buildings. Engineering structures (2013) 56: 1787-1799.

[16] Penna, A., Lagomarsino, S., \& Galasco, A. A nonlinear macroelement model for the seismic analysis of masonry buildings. Earthquake Engineering \& Structural Dynamics (2014) 43(2): 159-179.

[17] Bracchi, S., Mandirola, M., Rota, M. \& Penna, A. A new macroelement-based strategy for modelling reinforced masonry piers. 17th International Brick and Block Masonry Conference (2020).

[18] Ministero delle infrastrutture e dei trasporti. Aggiornamento delle Norme tecniche per le costruzioni. Gazzetta Ufficiale (2018). Rome, Italy.

[19] Magenes, G., \& Calvi, G. M. In-plane seismic response of brick masonry walls. Earthquake engineering \& structural dynamics (1997) 26(11): 1091-1112.

[20] Eurocode 6. Design of masonry structures. Part 1-1: General rules for buildings. Rules for reinforced and unreinforced masonry (2005). British Standard Institution, London.

[21] American Society of Civil Engineers (ASCE). ASCE/SEI 41-17: Seismic evaluation and retrofit of existing buildings (2017). Reston, Virginia, USA.

[22] American Wood Council (AWC). ANSI/AF\&PA SDPWS-2008: Special design provisions for wind and seismic (2018). Washington, DC. 